\title{
Anticancer Activity of Artemisinin and its Derivatives
}

\author{
SILVIA SLEZAKOVA and JANA RUDA-KUCEROVA
}

Department of Pharmacology, Faculty of Medicine, Masaryk University, Brno, Czech Republic

\begin{abstract}
Artemisinin is an extract from the plant Artemisia annua. With its semi-synthetic derivatives, they form a group of well-known and efficacious antimalarial drugs. Recent studies have documented the potential anticancer effect of artemisinin and its derivatives (ARTs). This review summarizes results of preclinical studies, documenting mechanisms of anticancer actions of ARTs and clinical studies focused mainly on efficacy, safety and dose-ranging of ARTs as anticancer chemotherapeutics. The main mechanisms of action of ARTs is the production of reactive oxygen species, inhibition of cell cycle in $G_{0} / G_{1}$ phase, induction of apoptosis and inhibition of angiogenesis. Safety studies have shown no evident toxicity and low incidence of adverse effects. ARTs potential to inhibit growth of solid tumours suggests their application in a neoadjuvant therapy. Dihydroartemisinin and artesunate exhibit chemosensitising effects in vivo in breast, lung, pancreas and glioma cancer cells, proposing the use of ARTs also in combination anticancer therapy.
\end{abstract}

Cancer remains one of the leading causes of death along with cardiovascular diseases and respiratory diseases in Europe. As the population is ageing, the risk of cancer is rising and so is the search of new chemotherapeutics aimed to fight cancer. It is mainly the patients with highly metastatic and aggressive cancers who benefit from alternative drugs to conventional chemotherapeutics, to which the cancer cells commonly develop drug resistance $(1,2)$. Herbs long time known and used today in traditional Chinese medicine present a large source of active substances and the aim of research of new chemotherapeutics against cancer.

Artemisia апnиa is a well and long-known Chinese medicinal plant that is often used in jaundice and hepatitis

Correspondence to: Jana Ruda-Kucerova, Ph.D., Department of Pharmacology, Faculty of Medicine, Masaryk University, Brno, Czech Republic. E-mail: jkucer@med.muni.cz

Key Words: Artemisinin, anticancer activity, Artesunate, dihydroartemisinin, review. treatment, also for reducing fever, nausea, headaches and excessive sweating caused by summer heat, parasitic infections and malaria. The earliest Chinese herbalist texts, dating back to 168 B.C. mention dried leafs of Artemisia аппиа mixed with other plants prepared as an infusion used for treatment of haemorrhoids and as a libido enhancer (3-5).

In the western medicine, artemisinin is widely used in malaria therapy. WHO recommendations include artemisininbased combination therapy as a first line treatment for uncomplicated malaria caused by Plasmodium falciparum (6). It is well tolerated and no significant side-effects are registered. Several studies demonstrated that artemisinin and its derivatives (ARTs) exhibit action against viruses and other parasites such as Schistosoma or Leishmania, but also against cancer (7). Observations that artemisinin inhibits the growth of many transformed cell lines have led to the hypothesis that the drug can also be useful for the treatment of human neoplasia.

As for the antimalarial effects, also the exact mechanisms that underlie the anticancer activities of ARTs remain elusive (8). However, the presence of the endoperoxide bridge and production of reactive oxygen species (ROS) is suggested as an important feature not only in antimalarial action but also in the fight against cancer cells (9). The aim of this review was to summarize current knowledge of artemisinin anticancer mechanisms of action and clinical trials evaluating its efficacy. The review is based on PubMed search for articles with the keywords "artemisinin anticancer", "artesunate cancer", "dihydroartemisinin cancer", "artemisinin mechanism", "artemisinin combination cancer" and terms "artemisinin", "artesunate", "dihydroartemisinin" on ClinicalTrials.gov.

\section{Source and Extraction of Artemisinin}

Artemisinin is a sesquiterpene lactone isolated from the Sweet Wormwood or Artemisia annua. Qinghao (the Chinese name for Artemisia annua) is belonging to the family of Asteraceae. It is an annual plant, native to China, nowadays cultivated in many countries around the world. Its height in natural condition is from 30 to $100 \mathrm{~cm}$, although if cultivated 
can reach up to $200 \mathrm{~cm}$. It takes about 8 months to reach the full size. With a brownish stem and specific leaves divided into two or three leaflets is characterized by an intensive sweetly aroma. The little flower heads are yellow and spherical, 2-2.5 $\mathrm{mm}$ in diameter and organised in panicles. Artemisinin is extracted mainly from the leaves. Plants are harvested usually at the beginning of flowering, at which time the content of artemisinin in leaves is the highest. The content of artemisinin itself is very small at around 0.01 to $1.4 \%$ of dry weight of plants. However new hybrid plants were cultivated in Switzerland, containing up to $2 \%$ of leaf artemisinin $(3,10,11)$.

China is the largest world supplier of Artemisia annua (providing together with Vietnam up to $70 \%$ of plant material annually), and the country of origin and first to extract artemisinin. It cooperates constantly and intensively with World Health Organization (WHO) on spreading the skills and technology in the cultivation of Artemisia annua (12). Therefore, China plays a key role in fight against malaria, but also widely engages in research of anticancer effects of artemisinin in countless studies aiming to introduce a new prospective oncology treatment.

The first isolation of artemisinin from the herb occurred in 1972 by a group led by Youyou Tu during a plant screening research program, under the name Project 523, set up in Beijing to find an adequate treatment for malaria. And it was Tu Youyou a Chinese female pharmaceutical chemist and a first Chinese Nobel laureate in physiology or medicine awarded in 2015 for a discovery of artemisinin (8).

After the plants being harvested and dried artemisinin, due to its poor solubility in water, is extracted using solvents, typically hexane. However there are different ways of extraction of artemisinin, varying in the content of artemisinin, depending on the solvent used for extraction. Nowadays the most frequently are decoction, liquid solvent extraction, pressurized solvent extraction, microwaveassisted extraction and supercritical fluid extraction (13).

The basic method of artemisinin extraction for industrial purposes involves the use of classic heated organic solvents, such as petroleum ether and hexane. To achieve reasonable balance between price and amount of extracted artemisinin, increased pressure, temperature of reactants or extended extraction time period are used in modern technologies. To eliminate other phytological compounds in extracted material the crystallization process is necessary for purifying artemisinin $(13,14)$.

Early after discovery of artemisinin and its anti-malaric activity, its semi-synthetic derivatives such as artemether, dihydroartemisinin, arteether, and artesunate have been developed. These compounds are considered to be about five times more effective to fight Plasmodium parasite and also the cancer cells. These derivatives can be obtained through chemical synthesis, recombinant DNA techniques or isolation from natural materials. However the last one remains still the most economical way (15).

The supply of artemisinin extracted from Artemisia annua is unstable through the year, depending on harvest. This issue complicates production of artemisinin-based therapeutics, therefore new biological syntheses are developing, using for example strains of Saccharomyces cerevisiae for highyielding production of artemisinic acid, precursor of artemisinin, presenting affordable and stable source of artemisinin. However, this approach is not yet available for industrial use (14).

\section{Mechanisms of Action of Artemisinin and its Derivatives (ARTs)}

Although ARTs are long known and effectively used as antimalarials, their specific biological action is poorly identified and understood. After discovery of its chemical structure being sesquiterpene lactone, the presence of chemically rare peroxide bond is thought to be crucial in its antimalarial action against Plasmodia in human body but also anticancer properties (16).

Within the cell, the ARTs being generally hydrophobic, they act mainly in membrane systems and have been found in localizations such as ER, food vacuoles, mitochondria and other. Current in vivo and in vitro studies propose numerous possible mechanisms of action. The most described and cited are: 1) oxidative stress, 2) induction of apoptosis, 3) inhibition of angiogenesis, 4) arrest of cell cycle at $G_{0} / G_{1}$ and 5) ferroptosis $(16,17)$.

Production of reactive oxygen species. Reactive oxygen species (ROS) are universal products of aerobic metabolism and their main source in human cells are mitochondria. They induce damage to the membranes, DNA, proteins, and organelles, playing an important role in cell autophagy and apoptosis. Production of ROS induced by dihydroartemisinin caused mitochondrial dysfunction and led to dihydroartemisinininduced autophagy of iron-loaded leukemia cell lines (18). ROS elicited from artemisinin and its different derivatives has been demonstrated to play an important role in ARTs-induced apoptosis in various tumor cell lines studies, including glioblastoma (19), T-cell lymphoma (20), neuroblastoma (21), breast cancer (22) and embryonal rhabdomyosarcoma cells (23). In a recent study on human hepatocellular carcinoma cells artesunate induced ROS-dependent apoptosis via a Baxmediated intrinsic pathway (24).

The role of ROS was studied also in vitro on a panel of ovarian cancer cell lines and in vivo in female mice model of ovarian cancer. Results of this study show inhibition of growth of ovarian cancer cells as well as the growth of tumour in a mouse model. Artesunate-treated ovarian cancer cells showed a strong induction of ROS and reduced 
proliferation. Depending on the concentration of artesunate, applied in cell cultures, ROS-dependent cell cycle arrest occurred in the $\mathrm{G}_{2} / \mathrm{M}$ phase whereas ROS-independent cell cycle arrest occurred in the $\mathrm{G}_{1}$ phase (9). This study has also cleared up some of the mechanism of anticancer activity of ARTs in human ovarian tumour and proposed their promising application mainly in patients with advanced ovarian cancer experiencing recurrent disease, often chemoresistant.

Induction of apoptosis. Induction of apoptosis was observed in spontaneously immortalized iatrogenic cell line of Kaposi's sarcoma treated with artesunate, a semisynthetic derivative of artemisinin. Apoptosis was detected using ELISA assay. As Kaposi's sarcoma derives from endothelial cells of the skin vasculature, human umbilical vascular endothelium (HUVE) cells have been used as a control and comparable target for treatment with artesunate. In contrary to Kaposi's sarcoma cells, no apoptosis was induced after $24 \mathrm{~h}$ respectively $48 \mathrm{~h}$ of application of artesunate in HUVE (25). Increased apoptosis rates and significant antiproliferative effect of artesunate in a dose-dependent manner was described in a study with human colorectal carcinoma cells. In addition, significant results in attenuating growth of human colorectal carcinoma was demonstrated in vitro and in vivo in mice xenografts. There was detected a connection between antiproliferative effect of artesunate and $\mathrm{Wnt} / \beta$-catenin pathway by immunofluorescence analysis (26). Wnt/ $\beta$-catenin pathway is important in embryonic processes as cell specification, cell proliferation and cell migration (27). Alterations and genetic mutations in this pathway thus leading to several human tumor diseases including colorectal, breast and prostate cancer (28).

Inhibition of angiogenesis. Neoplastic vascularization is important for tumor growth, supplying cancer cells with oxygen and nutrients. As well as for its metastatic spread, when tumor cells penetrate into the systemic blood circulation (29), which is typical for aggressive and rapidly growing tumours. The ability of the tumor cells to synthetize angiogenic factors is crucial and represent a target for anticancer drugs (30).

The antiangiogenic activity of antimalarial ARTs have been demonstrated in several studies. In a study with Kaposi's sarcoma-IMM cell lines, nude mice were injected subcutaneously with Matrigel pellets with VEGF (vascular endothelial growth factor), TNF $\alpha$ (tumor necrosis factor $\alpha$ ) and heparin as angiogenic stimuli. Artesunate was administered either directly to the Matrigel or given to the animals orally in the drinking water. After four days the pellets were recovered from mice, rinsed, weighted and the amount of haemoglobin in pellets was measured to estimate effect of artesunate. Strong vascularization and presence of functional blood filled vessels were present in the samples without administration of artesunate and drastically reduced vascularization was observed in the pellets containing artesunate (25). Similarly, down-regulation of VEGF expression and suppression of angiopoietin 1 secretion induced by artesunate were reported in a study with multiple myeloma cells (31). The effect of artesunate on aortic sprouting was analyzed in vitro on chronic myeloid leukemia K562 cells. The angiogenesis in aortic sprouting was induced by cultivating in conditioned media from K562, chronic myelogenous leukemia cell line. When pretreated with artesunate the number of new microvessels in sample was markedly reduced, in a time-dependent and dose-dependent manner proving antiproliferative effect of artesunate (32).

Cell-cycle arrest. Uncontrolled cell division is one of the basic characteristics of cancer cells. ARTs showed the ability of arresting the cell cycle by changing expression and activity of several regulatory enzymes. In human Ishikawa endometrial cancer cells artemisinin induced a $G_{1}$ cell cycle arrest and downregulated cyclin-dependent kinase-4 (CDK4) gene expression by disruption of nuclear factor- $\mathrm{kB}(\mathrm{NF}-\mathrm{kB})$ interactions with the CDK4 promoter (33). $\mathrm{G}_{1}$-phase arrest was also induced in gallbladder cancer cells treated with artemisinin. In this case the cell cycle arrest was linked with decreased expression of CDK4 and cyclin D1 and an increase in a tumour suppressor protein p16 expression (34). Artesunate caused $\mathrm{G}_{2} / \mathrm{M}$ cell cycle arrest in breast cancer cells by upregulating the expression of Beclin1, initiator of autophagy (35). In a study on pancreatic cancer cell lines the treatment with dihydroartemisinin resulted in a dosedependent $G_{0} / G_{1}$ cell cycle arrest affecting the expression of cell cycle regulatory enzymes, such as cyclin E, CDK2, CDK4 and p27. Furthermore, dihydroartemisinin inhibited the translocation and DNA-binding activity of NF- $\mathrm{kB}$, proposing this one as a target of dihydroartemisinins growth inhibitory effect on cancer cell lines (36).

Ferroptosis. Lately the mechanism of action of dihydroartemisinin in head and neck squamous cell carcinoma (HNSCC) cells was also studied, based on known antimalarial mode of action of ARTs, comprehending $\mathrm{Fe}^{2+}$ ions and proposed the hypothesis of ferroptosis (37). Ferroptosis represents a specific form of programmed cell death caused by the iron-dependent accumulation of lipid reactive oxygen species and depletion of plasma membrane polyunsaturated fatty acids (38). In a study on HNSCC cells treated with dihydroartemisinin, increased ROS levels were found. This increase was prevented by an iron chelator desferrioxamine. These results show that dihydroartemisinin requires iron to induce cell death in HNSCC cells. The mitochondrial morphology changes, typical for ferroptotic cells were also observed (37). As iron is needed for DNA 
synthesis and tumour cells use it for their rapid growth, it is possible that higher levels of iron are target and explain the specific activity of dihydroartemisinin on tumour cells. Another evidence supporting the hypothesis of ferroptosis are the decreased levels of GPx4 and Ras in dihydroartemisinin-treated HNSCC cells, as both GPx4 and Ras are important regulators of ferroptosis (37).

\section{Artemisinin in Combination with Other Anticancer Drugs}

Combination chemotherapy is nowadays the standard of care aiming at maximizing efficacy and minimizing systemic toxicity at the same time. Multiple mechanisms of action of ARTs, which differ from traditional chemotherapeutics propose the possibility of effective synergism of these two. It has been reported that resistant cancer cell lines become sensitive by adding artemisinin and its derivatives to the conventional treatment (chemosensitization) (15). Artesunate showed the ability of sensitizing breast cancer cells to epirubicin in an autophagy cascade-dependent manner. In contrast, artesunate did not significantly increase the cytotoxicity of docetaxel, another commonly used anticancer drug in breast cancer (35).

Shuang-Jia Wang et al. (2010) demonstrated in their study a synergism of dihydroartemisinin and gemcitabine on pancreatic cancer cells. Significant increase of apoptosis, decreased Ki-67 index, decreased NF-KB activity and its related gene products such as c-myc, cyclin D1, Bcl-2, $\mathrm{Bcl}-\mathrm{xL}$ were manifested. Inhibition of gemcitabine-induced NF- $\mathrm{KB}$ activation is believed to be the main mechanism dihydroartemisinin acts in synergism with gemcitabine against pancreatic tumour cells (36).

Effective combination of dihydroartemisinin and traditional chemotherapeutics used for treatment of lung carcinomas, cyclophosphamide and cisplatin was shown in a murine Lewis lung carcinoma and the human non-small cell lung cancer models in mice. Both combination of high dose dihydroartemisinin and cyclophosphamide and dihydroartemisinin and cisplatin induced significant reduction of tumour volume compared with either therapy alone. Moreover, the incidence of spontaneous pulmonary metastasis was completely inhibited by the combination of dihydroartemisinin with cyclophosphamide (39).

Dihydroartemisinin potentiated the cytotoxic effect of temozolomide, in glioma cells, mainly by generating reactive oxygen species. Dihydroartemisinin increased temozolomide-induced apoptosis and necrosis in dose dependent way (40). Furthermore, increased apoptosis was observed in human hepatoma cells HepG2 (p53 wild-type), Huh-7, BEL-7404 (p53 mutant) and Hep3B after treatment with two combinations: dihydroartemisinin and gemcitabine, and artemisinin and gemcitabine. Similarly, in mouse models of human hepatoma carcinoma both combinations significantly decreased tumor growth. In all xenograft models dihydroartemisinin showed greater, dose-dependent therapeutic effects compared with artemisinin (41).

These lines of evidence suggest that ARTs, mainly dihydroartemisinin and artesunate, possess the chemosensitising effects and propose their future use in the fight with chemoresistant carcinomas.

\section{Clinical Studies}

To date, there is a great number of in vitro and in vivo studies, describing anticancer effects of ARTs with encouriging results. Also several case reports documenting reducing effect of ARTs on tumour size and growth were published (42). However, only few clinical trials with oncological patients were completed and their results published. The most studied are patients with solid tumours: colorectal carcinoma, breast cancer, hepatocellular carcinoma and lung cancer. Different clinical trials mostly Phases 1 and 2 are in progress, recruiting also patients with intra-epithelial neoplasia $(43,44)$. Table I summarizes the results of completed clinical trials and trials in progress. Number of participating patients, specific drug, dose and route of administration is included.

The efficacy and toxicity of artesunate as an add-on therapy in patients with advanced non-small cell lung cancer (NSCLC) was studied by Zhang ZY et al. (45). They recruited 120 patients with NSCLC, randomly divided them into control group receiving NP (a chemotherapy regimen of vinorelbine and cisplatin) and trial group, treated with artesunate combined with chemotherapy. At least two 21-day cycles of treatment were performed. The results showed no significant differences in the short-term survival rate, mean survival time and 1-year survival rate between the trial group and the control group. However significant differences appeared in disease control rate. Disease control rate of the trial group $(88.2 \%)$ was significantly higher than that of the control group $(72.7 \%)(p<0.05)$. Moreover the trial group's time to progression was 24 weeks significantly longer than that of the control group (20 weeks). There was no significant differences found in toxicity between the two groups, such as myelosuppression or digestion reaction leading to conclusion that artesunate seems to be safe to be used in the treatment of NSCLC (45).

Results of another safety and efficacy study were published in 2011 by Jansen FH et al. Patients with advanced cervical cancer were treated by oral artenimol-R (dihydroartemisinin) for 28 days and the levels of tumour markers were measured afterwards. A decrease of expression of p53, EGFR, and antigen Ki-67, a cellular marker of proliferation was evidenced. Moreover the number of blood vessels stained by the CD31 antibody was reduced, whereas 
the expression of transferrin receptor protein 1 (CD71) increased. Treatment with dihydroartemisinin induced clinical remission in all patients, with a median time for the disappearance of the symptoms being 7 days (46). Despite the results of this study are encouraging, the number of patients participated in this study is low and call for a clinical trial with larger group of patients to obtain more reliable results.

Anticancer effect and tolerability of oral artesunate in colorectal cancer patients was evaluated in a single centre, randomised, double-blind, placebo-controlled trial. There were twenty patients who completed the trial per protocol. They received either 14 daily doses of oral artesunate (200 $\mathrm{mg}$ ) or placebo preoperatively before the curative resection of single primary site colorectal carcinoma. The primary outcome (significant apoptosis in the epithelial cells of the tumour specimen defined as $>7 \%$ of cells with apoptotic features) was achieved in 55\% of placebo recipients and $67 \%$ of artesunate treated patients. With even more encouraging secondary outcomes: Artesunate manifested a very high probability $(0.97$, calculated with an informative prior in Bayesian analysis) of effect on Ki-67 staining of tumour cells (Ki-67 being a marker of tumour cell proliferation) and 0.79 probability for increased CD31 expression. And there was a $\sim 75 \%$ fall in circulating CEA levels after 2 weeks of treatment only with artesunate in one case (47). The same team launched in October 2016 a Safety and Effectiveness Study of Preoperative Artesunate in Stage II/III Colorectal Cancer, recruiting 200 patients, with similar inclusion criteria as in the previous study from 2014. Patients will be followed up closely for 5 years after treatment with artesunate to review the effect of artesunate on recurrence free survival of patients and the safety and tolerability of artesunate (48). Another Phase 2 clinical trial recruiting patients with histologically confirmed Stage II/III colorectal cancer awaiting surgical treatment is in progress in the 108 Military Central Hospital in Vietnam. Artesunate will be given orally in dose of $200 \mathrm{mg}$ once a day for 14 days to patients awaiting surgical treatment with curative intent and recurrence free survival 2 years after surgery will be compared with control placebo group as a primary outcome (48).

A rapid dose escalation design (as shown in Table I) was used to determine maximum tolerated dose of intravenous artesunate for treatment 19 patients with different solid tumours. This Phase 1 study started in January 2015 on Georgetown University and the results were not yet published (49). Pharmacokinetics of artesunate and dihydroartemisinin in patients with metastatic breast cancer was studied by Ericsson et al. They analysed plasma and saliva samples from 23 female patients treated with 100,150 or $200 \mathrm{mg}$ oral artesunate for at least 3 weeks. The combined drug (artesunate) and metabolite (dihydroartemisinin) model characterized the population pharmacokinetic properties of artesunate in plasma. Results showed a $24.9 \%$ increase in apparent elimination clearance of dihydroartemisinin after daily treatment with oral artesunate for $>3$ weeks, suggesting a potential autoinduction of metabolism. Moreover the concentrations of salivary and plasma dihydroartemisinin correlated and proposed a possible use of saliva samples in further pharmacokinetic investigations (50). The pharmacokinetics and safety of artesunate in patients with hepatocellular carcinoma was evaluated in Phase 1 study recruiting patients in the University hospital in Ghent. Artesunate was administrated orally in dose-escalation manner. As a measure of safety and tolerability was studied the number of participants with adverse events and the maximum tolerated dose in the time frame of 14 days. Neither results of pharmacokinetic analysis, nor safety and tolerability results were yet published (51).

Another Phase 1 study searched for well-tolerated dose of oral artesunate as add-on therapy in patients with metastatic breast cancer. During four weeks 106 adverse effects were observed in 23 female patients treated with oral artesunate. No adverse effects were probably or certainly related to the artesunate add-on therapy to guideline-based oncological therapy. However adverse effects such as leucopenia, neutropenia, anemia and vertigo were observed possibly related to the artesunate add-on therapy. Most side-effects resolved spontaneously after treatment with artesunate was finished and no neurotoxic, ototoxic or hepatotoxic effects were reasons for individual discontinuation of treatment. As safety and tolerability did not reach an upper limit, the dose $200 \mathrm{mg} / \mathrm{d}(2.2-3.9 \mathrm{mg} / \mathrm{kg} / \mathrm{d})$ was suggested for Phase 2 trials with regular monitoring of reticulocytes, NTproBNP and neurological, and audiological examinations (52). In the same clinical trial the possible side effects of artesunate on auditory system were investigated. Four patients resulted having adverse events of the auditory system possibly related to the intake of artesunate (none of these classified as severe) but did not require treatment interruption. And four patients observed problems with the vestibular system (vertigo), one of which was classified as severe adverse effect, nevertheless was fully reversible after discontinuation of artesunate. No dose-limiting auditory toxicity was proved after 4 weeks of therapy with artesunate (53).

Among studies with no results published at present, there is a Phase 1/2a study, run by Guy's and St Thomas NHS Foundation Trust in London. Artemether will be given to patients with advanced solid tumour as a sublingual spray for four months. And they will search for the highest safe dose of artemether in the Phase 1 and the effect on growth of the tumour in the Phase 2 (54). New studies recruiting patients with intraepithelial neoplasia are in progress in several medical centers in Maryland, USA (43, 44). Estimated completion date of these studies is February and March 2019 respectively. Patients with cervical intraepithelial neoplasia 
Table I. Clinical trials evaluating anticancer effects of ARTs.

\begin{tabular}{|c|c|c|c|c|c|c|}
\hline Status & $\begin{array}{l}\text { Type of } \\
\text { cancer }\end{array}$ & Phase & $\begin{array}{l}\text { No. of } \\
\text { patients }\end{array}$ & Drug, dose & Key results & Reference \\
\hline Results & Colorectal ca & Phase 1 & 20 & $\begin{array}{l}14 \text { daily doses of neoadjuvant oral } \\
\text { artesunate } 200 \mathrm{mg} \text { in trial group or } \\
\text { a matching placebo in control group }\end{array}$ & $\begin{array}{c}\text { Apoptosis in }>7 \% \text { of cells in } 67 \% \\
\text { Reduced Ki67 expression ( } 0.89 \text { prob.) } \\
\text { Increased CD31 expression ( } 0.79 \text { prob. }) \\
\text { Adverse events: neutropenia }\end{array}$ & $(47)$ \\
\hline Results & Cervical ca & Phase 1 & 10 & Oral dihydroartemisinin for 28 days & $\begin{array}{c}\text { Decreased expression of p53 } \\
\text { Decreased expression of EGFR } \\
\text { Decreased expression of Ki-67 } \\
\text { Decreased number of blood vessels } \\
\text { No adverse events of grade } 3 \text { or } 4\end{array}$ & $(46)$ \\
\hline Results & $\begin{array}{c}\text { Metastatic } \\
\text { breast ca }\end{array}$ & Phase $0 / 1$ & 23 & $\begin{array}{l}\text { Artesunate add-on therapy } \\
100,150 \text { or } 200 \mathrm{mg} \text { oral artesunate } \\
\text { daily during four weeks }\end{array}$ & $\begin{array}{c}\text { Safety and tolerability of artesunate } \\
\text { at dose } 200 \mathrm{mg} / \mathrm{d}(2.2-3.9 \mathrm{mg} / \mathrm{kg} / \mathrm{d}) \\
\text { Phase } 2 \text { trials suggested } \\
\text { Adverse events: leucopenia, } \\
\text { neutropenia, anemia, vertigo }\end{array}$ & $(52)$ \\
\hline Results & $\begin{array}{c}\text { Metastatic } \\
\text { breast ca }\end{array}$ & Phase 1 & 23 & $\begin{array}{l}\text { Oral artesunate } 100,150, \text { or } \\
200 \mathrm{mg} \text { daily }>3 \text { weeks }\end{array}$ & $\begin{array}{c}\text { A } 24.9 \% \text { increase in apparent } \\
\text { elimination clearance of } \\
\text { dihydroartemisinin } \\
\text { (combined drug-metabolite model) } \\
\text { Possible use of saliva sampling in } \\
\text { pharmacokinetic investigations suggested }\end{array}$ & $(50)$ \\
\hline Results & $\begin{array}{l}\text { Advanced } \\
\text { non-small cell } \\
\text { lung cancer } \\
\text { (NSCLC) }\end{array}$ & Phase 1 & 120 & $\begin{array}{l}\text { Artesunate }(120 \mathrm{mg} \text {, once-a-day } \\
\text { intravenous injection, from the } \\
\text { 1st day to 8th day, for } 8 \text { days) with } \\
\text { the basal therapy NP (vinorelbine } \\
\text { and cisplatin) in trial group } \\
\text { or basal therapy NP } \\
\text { in control group }\end{array}$ & $\begin{array}{c}\text { No significant differences in the } \\
\text { short-term survival rate, } \\
\text { MST and 1-year survival rate } \\
\text { DCR of the trial group } 88.2 \% \\
\text { DCR of the control group } 72.7 \% \text { trial } \\
\text { group's time to progression } 24 \text { weeks the } \\
\text { control group's time to progression } 20 \text { weeks } \\
\text { No significant difference was found } \\
\text { in toxicity between the two groups }\end{array}$ & $(45)$ \\
\hline Recruiting & $\begin{array}{c}\text { Colorectal ca } \\
\text { Stage II/III }\end{array}$ & Phase 2 & 200 & $\begin{array}{l}\text { Neoadjuvant artesunate given orally } \\
\text { as a dose of } 200 \mathrm{mg} \text { once a day for } \\
14 \text { days in trial group or a matching } \\
\text { placebo for } 14 \text { days in control group }\end{array}$ & $\begin{array}{c}\text { Estimated Completion Date: May } 2023 \\
\text { Outcomes: } \\
\text { Recurrence free survival at } \\
2 \text { years after surgery } \\
\text { Adverse events } \\
\text { Patient quality of life }\end{array}$ & $(48)$ \\
\hline Completed & $\begin{array}{c}\text { Advanced } \\
\text { solid tumours }\end{array}$ & Phase $1 / 2 \mathrm{a}$ & 87 & $\begin{array}{l}\text { Artemether sublingual spray } \\
20 \mathrm{mg} \text { for } 4 \text { cycles of escalation } \\
\text { dosing, } 28 \text { days per cycle }\end{array}$ & $\begin{array}{c}\text { Estimated Completion Date: October } 2016 \\
\text { Outcomes: } \\
\text { Determinate recommended Phase } 2 \text { Dose } \\
\text { No. of patients with complete or } \\
\text { partial response, stable disease at } \\
16 \text { weeks, reduction of validated } \\
\text { biomarkers in Phase } 2 \mathrm{a}\end{array}$ & $(54)$ \\
\hline Recruiting & $\begin{array}{l}\text { Stage II/III } \\
\text { Colorectal } \\
\text { Cancer }\end{array}$ & Phase 2 & $\begin{array}{c}200 \\
\text { estimated }\end{array}$ & $\begin{array}{l}\text { Artesunate given orally as a dose } \\
\text { of } 200 \mathrm{mg} \text { once a day } \\
\text { for } 14 \text { days in trial group } \\
\text { or a matching placebo for } \\
14 \text { days in control group }\end{array}$ & $\begin{array}{c}\text { Estimated Completion Date: December } 2021 \\
\text { Outcomes: } \\
\text { Recurrence free survival } 2 \\
\text { years after surgery }\end{array}$ & $(48)$ \\
\hline Recruiting & $\begin{array}{l}\text { HPV-associated } \\
\text { anal } \\
\text { intraepithelial } \\
\text { neoplasia } \\
\text { AIN } 2 / 3\end{array}$ & Phase 1 & $\begin{array}{c}18 \\
\text { estimated }\end{array}$ & $\begin{array}{l}\text { Artesunate suppositories } \\
\text { trans-anally in escalated } \\
\text { doses } 200 \mathrm{mg}, 400 \mathrm{mg}, 600 \mathrm{mg} \\
\text { daily for } 5 \text { days up to } 3 \text { cycles }\end{array}$ & $\begin{array}{c}\text { Estimated Completion Date: March } 2019 \\
\text { Outcomes: } \\
\text { Regression of anal intraepithelial neoplasia } \\
\text { Clearance of AIN2/3 disease } \\
\text { Clearance of human papillomavirus (HPV) virus }\end{array}$ & $(44)$ \\
\hline Recruiting & $\begin{array}{l}\text { Cervical } \\
\text { Intraepithelial } \\
\text { Neoplasia } \\
\text { Grade } 2 / 3 \\
\text { High risk HPV }\end{array}$ & Phase 1 & $\begin{array}{c}30 \\
\text { estimated }\end{array}$ & $\begin{array}{l}\text { Intravaginal artesunate in } \\
\text { suppositories for up to a } \\
\text { total of three cycles }\end{array}$ & $\begin{array}{c}\text { Estimated Completion Date: February } 2019 \\
\text { Outcomes: } \\
\text { Histologic regression of CIN2/3 } \\
\text { [Time Frame: } 28 \text { weeks] }\end{array}$ & $(43)$ \\
\hline
\end{tabular}


Table I. Continued

\begin{tabular}{|c|c|c|c|c|c|c|}
\hline Status & $\begin{array}{l}\text { Type of } \\
\text { cancer }\end{array}$ & Phase & $\begin{array}{l}\text { No. of } \\
\text { patients }\end{array}$ & Drug, dose & Key results & Reference \\
\hline Completed & Solid tumours & Phase 1 & 19 & $\begin{array}{l}\text { Intravenous artesunate in } \\
\text { escalating doses: } 8,12,18,25 \text {, } \\
34,45 \mathrm{mg} / \mathrm{kg} \text { on days } 1 \text { and } \\
8 \text { of every } 3 \text { week cycles }\end{array}$ & $\begin{array}{c}\text { Outcomes: } \\
\text { Maximum Tolerated } \\
\text { Dose [Time Frame: } 1 \text { year] }\end{array}$ & (49) \\
\hline Completed & $\begin{array}{l}\text { Advanced } \\
\text { hepatocellular } \\
\text { carcinoma }\end{array}$ & Phase 1 & 15 & $\begin{array}{l}\text { Oral artesunate once-daily for } \\
14 \text { days, dose-escalation }\end{array}$ & $\begin{array}{c}\text { Outcomes: } \\
\text { Number of Participants with } \\
\text { Adverse Events [Time Frame: } 14 \text { days] } \\
\text { Maximum tolerated dose [Time Frame: } 14 \text { days] } \\
\text { Pharmacokinetic analysis of Cmax, Cmin, } \\
\text { Tmax, and AUC. [Time Frame: } 2 \text { days] }\end{array}$ & ] \\
\hline
\end{tabular}

(CIN2/3) associated with high risk HPV and patients with HPV-associated anal intraepithelial neoplasia (AIN 2/3) will be treated by artesunate suppositories and the histologic regression, the possible clearance of HPV as well as the artesunate doses will be evaluated.

\section{Conclusion and Future Perspectives}

ARTs represent an efficacious antimalarial drug group with an excellent safety profile. Their anticancer properties have been documented in multiple preclinical and clinical studies. ARTs effectively reduce the growth of solid tumours by inhibition of angiogenesis, induction of apoptosis and ferroptosis, production of reactive oxygen species and induction of cellcycle arrest. As new, modern technologies of research progress, the more detailed information about different mechanisms of action of ARTs rise. The current number of clinical trials is increasing and the results are encouraging. ARTs may become an alternative for adjuvant or neodjuvant treatment of solid tumours, specifically breast, pancreas, colorectal or lung and other cancer. The possible regressive effect on cervical and anal intraepithelial neoplasia may lead to less invasive treatment procedures. The chemosensiting effect of artesunate and dihydroartemisinin suggests the use of ARTs as an add-on therapy in combination with conventional chemotherapeutics and it is to be studied in future clinical trials. ARTs may represent one of many examples of power hidden in natural sources and after many years of research may become new promising anticancer drugs, hopefully developed and introduced to clinical use in the near future.

\section{Conflicts of Interest}

The Authors state that there are no conflicts of interest regarding the publication of this article.

\section{Acknowledgements}

This study was written at Masaryk university as part of the project Experimental and translational pharmacological research and development" number MUNI/A/1063/2016 with the support of the Specific University Research Grant, as provided by the Ministry of Education, Youth and Sports of the Czech Republic in the year 2017.

\section{References}

1 Caffrey PB, Frenkel GD, McAndrew KL and Marks K: A model of the development of cisplatin resistance in human small cell lung cancer xenografts. In Vivo 30(6): 745-749, 2016.

2 Cruz IN, Coley HM, Kramer HB, Madhuri TK, Safuwan NAM, Angelino AR and Yang M: Proteomics analysis of ovarian cancer cell lines and tissues reveals drug resistance-associated proteins. Cancer Genomics Proteomics 14(1): 35-51, 2017.

3 Rombauts K, Heyerick A and CAM-Cancer Consortium: Artemisia апnиа/Herbal products/CAM-Cancer, 2015. Available from: http://www.cam-cancer.org/The-Summaries/Herbal-products/ Artemisia-annua/(merge) [last accessed August 31, 2017].

4 Chao J, Dai Y, Verpoorte R, Lam W, Cheng Y-C, Pao L-H, Zhang W and Chen S: Major achievements of evidence-based traditional Chinese medicine in treating major diseases. Biochem Pharmacol 139: 94-104, 2017.

$5 \mathrm{Fu} \mathrm{J-C:} \mathrm{Artemisinin} \mathrm{and} \mathrm{chinese} \mathrm{medicine} \mathrm{as} \mathrm{Tu} \mathrm{science.}$ Endeavour 41(3): 127-135, 2017

6 Nosten F and White NJ: Artemisinin-Based Combination Treatment of Falciparum Malaria. In: Defining and Defeating the Intolerable Burden of Malaria III: Progress and Perspectives: Supplement to Volume 77(6) of American Journal of Tropical Medicine and Hygiene. Breman JG, Alilio MS, White NJ, editors.t. Northbrook (IL), American Society of Tropical Medicine and Hygiene, 2007.

$7 \mathrm{Li} \mathrm{J}$ and Zhou B: Biological Actions of Artemisinin: Insights from Medicinal Chemistry Studies. Molecules 15(3): 1378-1397, 2010.

8 Efferth T: Willmar Schwabe Award 2006: Antiplasmodial and Antitumor Activity of Artemisinin - From Bench to Bedside. Planta Med 73(4): 299-309, 2007. 
9 Greenshields AL, Shepherd TG and Hoskin DW: Contribution of reactive oxygen species to ovarian cancer cell growth arrest and killing by the anti-malarial drug artesunate. Mol Carcinog 56(1): 75-93, 2017.

10 Woerdenbag HJ, Lugt CB and Pras N: Artemisia annua L.: a source of novel antimalarial drugs. Pharm Weekbl Sci 12(5): 169-181, 1990.

11 Brown GD: The Biosynthesis of Artemisinin (Qinghaosu) and the Phytochemistry of Artemisia annua L. (Qinghao). Molecules 15(11): 7603-7698, 2010.

12 World Heatlh Organization: WHO monograph on good agricultural and collection practices (GACP) for Artemisia аппиа L., 2006.

13 Sánchez D, Quispe S, Rosa P, Meireles MAA, Zetzl C and Brunner G: Extraction of the antimalarial artemisinin from Artemisia annua L. leaves with supercritical $\mathrm{CO}_{2}$. Versailles, France, 2003.

14 Paddon CJ, Westfall PJ, Pitera DJ, Benjamin K, Fisher K, McPhee D, Leavell MD, Tai A, Main A, Eng D and others: High-level semi-synthetic production of the potent antimalarial artemisinin. Nature 496(7446): 528, 2013.

15 Crespo-Ortiz MP and Wei MQ: Antitumor activity of artemisinin and its derivatives: from a well-known antimalarial agent to a potential anticancer drug. J Biomed Biotechnol 2012: 247597, 2012.

16 Krishna S, Bustamante L, Haynes RK and Staines HM: Artemisinins: their growing importance in medicine. Trends Pharmacol Sci 29(10): 520-527, 2008.

17 Das A: Anticancer effect of antimalarial artemisinin compounds. Ann Med Health Sci Res 5(2): 93, 2015.

18 Wang $\mathrm{Z}, \mathrm{Hu} \mathrm{W}$, Zhang J-L, Wu X-H and Zhou H-J: Dihydroartemisinin induces autophagy and inhibits the growth of iron-loaded human myeloid leukemia K562 cells via ROS toxicity. FEBS Open Bio 2(1): 103-112, 2012.

19 Berte N, Lokan S, Eich M, Kim E and Kaina B: Artesunate enhances the therapeutic response of glioma cells to temozolomide by inhibition of homologous recombination and senescence. Oncotarget 7(41): 67235-67250, 2016.

20 Wang Q, Wu S, Zhao X, Zhao C, Zhao $\mathrm{H}$ and Huo L: Mechanisms of Dihydroartemisinin and Dihydroartemisinin/ Holotransferrin Cytotoxicity in T-Cell Lymphoma Cells. PLOS ONE 10(10): e0137331, 2015.

21 Michaelis M, Kleinschmidt MC, Barth S, Rothweiler F, Geiler J, Breitling R, Mayer B, Deubzer H, Witt O, Kreuter J, Doerr $\mathrm{HW}$, Cinatl $\mathrm{J}$ and Cinatl $\mathrm{J}$ : Anti-cancer effects of artesunate in a panel of chemoresistant neuroblastoma cell lines. Biochem Pharmacol 79(2): 130-136, 2010.

22 Hamacher-Brady A, Stein HA, Turschner S, Toegel I, Mora R, Jennewein N, Efferth T, Eils R and Brady NR: Artesunate activates mitochondrial apoptosis in breast cancer cells via ironcatalyzed lysosomal reactive oxygen species production. J Biol Chem 286(8): 6587-6601, 2011.

23 Beccafico S, Morozzi G, Marchetti MC, Riccardi C, Sidoni A, Donato R and Sorci G: Artesunate induces ROS- and p38 MAPK-mediated apoptosis and counteracts tumor growth in vivo in embryonal rhabdomyosarcoma cells. Carcinogenesis 36(9): 1071-1083, 2015.

24 Pang Y, Qin G, Wu L, Wang X and Chen T: Artesunate induces ROS-dependent apoptosis via a Bax-mediated intrinsic pathway in Huh-7 and Hep3B cells. Exp Cell Res 347(2): 251-260, 2016.
25 Dell'Eva R, Pfeffer U, Vené R, Anfosso L, Forlani A, Albini A and Efferth T: Inhibition of angiogenesis in vivo and growth of Kaposi's sarcoma xenograft tumors by the anti-malarial artesunate. Biochem Pharmacol 68(12): 2359-2366, 2004.

26 Li L-N, Zhang H-D, Yuan S-J, Tian Z-Y, Wang L and Sun Z-X: Artesunate attenuates the growth of human colorectal carcinoma and inhibits hyperactive $\mathrm{Wnt} / \beta$-catenin pathway. Int J Cancer 121(6): 1360-1365, 2007.

27 Denysenko T, Annovazzi L, Cassoni P, Melcarne A, Mellai M and Schiffer D: WNT/ $\beta$-catenin Signaling Pathway and Downstream Modulators in Low- and High-grade Glioma. Cancer Genomics Proteomics 13(1): 31-45, 2016.

28 Logan CY and Nusse R: The Wnt signaling pathway in development and disease. Annu Rev Cell Dev Biol 20(1): 781810, 2004.

29 Weidle UH, Birzele F, Kollmorgen G and Rueger R: The multiple roles of exosomes in metastasis. Cancer Genomics Proteomics 14(1): 1-15, 2017.

30 Zetter, PhD BR: Angiogenesis and Tumor Metastasis. Annu Rev Med 49(1): 407-424, 1998.

31 Chen H, Shi L, Yang X, Li S, Guo X and Pan L: Artesunate inhibiting angiogenesis induced by human myeloma RPMI8226 cells. Int J Hematol 92(4): 587-597, 2010.

32 Zhou H-J, Wang W-Q, Wu G-D, Lee J and Li A: Artesunate inhibits angiogenesis and downregulates vascular endothelial growth factor expression in chronic myeloid leukemia K562 cells. Vascul Pharmacol 47(2): 131-138, 2007.

33 Tran KQ, Tin AS and Firestone GL: Artemisinin triggers a G1 cell cycle arrest of human Ishikawa endometrial cancer cells and inhibits Cyclin Dependent Kinase-4 promoter activity and expression by disrupting NF-kB transcriptional signaling. Anticancer Drugs 25(3): 270-281, 2014.

34 Jia J, Qin Y, Zhang L, Guo C, Wang Y, Yue X and Qian J: Artemisinin inhibits gallbladder cancer cell lines through triggering cell cycle arrest and apoptosis. Mol Med Rep 13(5): 4461-4468, 2016.

35 Chen K, Shou L-M, Lin F, Duan W-M, Wu M-Y, Xie X, Xie YF, Li W and Tao M: Artesunate induces G2/M cell cycle arrest through autophagy induction in breast cancer cells. Anticancer Drugs 25(6): 652-662, 2014.

36 Wang S-J, Gao Y, Chen H, Kong R, Jiang H-C, Pan S-H, Xue D$\mathrm{B}$, Bai X-W and Sun B: Dihydroartemisinin inactivates NF-kB and potentiates the anti-tumor effect of gemcitabine on pancreatic cancer both in vitro and in vivo. Cancer Lett 293(1): 99-108, 2010.

37 Lin R, Zhang Z, Chen L, Zhou Y, Zou P, Feng C, Wang L and Liang G: Dihydroartemisinin (DHA) induces ferroptosis and causes cell cycle arrest in head and neck carcinoma cells. Cancer Lett 381(1): 165-175, 2016.

38 Yang WS, SriRamaratnam R, Welsch ME, Shimada K, Skouta R, Viswanathan VS, Cheah JH, Clemons PA, Shamji AF, Clish $\mathrm{CB}$ and others: Regulation of ferroptotic cancer cell death by GPX4. Cell 156(1): 317-331, 2014.

39 Zhou H-J, Zhang J-L, Li A, Wang Z and Lou X-E: Dihydroartemisinin improves the efficiency of chemotherapeutics in lung carcinomas in vivo and inhibits murine Lewis lung carcinoma cell line growth in vitro. Cancer Chemother Pharmacol 66(1): 21-29, 2010.

40 Huang X-J, Li C-T, Zhang W-P, Lu Y-B, Fang S-H and Wei E-Q: Dihydroartemisinin potentiates the cytotoxic effect of temozolomide in rat C6 glioma cells. Pharmacology 82(1): 1-9, 2008. 
41 Hou J, Wang D, Zhang R and Wang H: Experimental therapy of hepatoma with artemisinin and its derivatives: in vitro and in vivo activity, chemosensitization, and mechanisms of action. Clin Cancer Res 14(17): 5519-5530, 2008.

42 Singh $\mathrm{N}$ and Verma K: Case report of a laryngeal squamous cell carcinoma treated with artesunate. Arch Oncol 10(4): 279-280, 2002.

43 Intravaginal Artesunate for the Treatment of HPV+ High Grade Cervical Intraepithelial Neoplasia (CIN2/3) - Full Text View ClinicalTrials.gov. Available from: https://clinicaltrials.gov/ ct2/show/NCT02354534 [last accessed August 31, 2017].

44 Intra-Anally Administered Artesunate in Patients With HighGrade Anal Intraepithelial Neoplasia (AIN 2/3) - Full Text View - ClinicalTrials.gov. Available from: https://clinicaltrials.gov/ ct2/show/NCT03100045 [last accessed August 31, 2017].

45 Zhang ZY, Yu SQ, Miao LY, Huang XY, Zhang XP, Zhu YP, Xia $\mathrm{XH}$ and Li DQ: Artesunate combined with vinorelbine plus cisplatin in treatment of advanced non-small cell lung cancer: a randomized controlled trial. Zhong Xi Yi Jie He Xue Bao 6(2): 134-138, 2008

46 Jansen FH, Adoubi I, JC KC, De Cnodder T, Jansen N, Tschulakow A and Efferth T: First study of oral Artenimol-R in advanced cervical cancer: clinical benefit, tolerability and tumor markers. Anticancer Res 31(12): 4417-4422, 2011.

47 Krishna S, Ganapathi S, Ster IC, Saeed ME, Cowan M, Finlayson C, Kovacsevics H, Jansen H, Kremsner PG, Efferth T and others: A randomised, double blind, placebo-controlled pilot study of oral artesunate therapy for colorectal cancer. EBioMedicine 2(1): 82-90, 2015.

48 A Safety and Effectiveness Study of Pre-operative Artesunate in Stage II/III Colorectal Cancer - Full Text View ClinicalTrials.gov. Available from: https://clinicaltrials.gov/ct2/ show/NCT02633098 [last accessed August 31, 2017].

49 Phase I Study of Intravenous Artesunate for Solid Tumors - Full Text View - ClinicalTrials.gov. Available from: https:// clinicaltrials.gov/ct2/show/NCT02353026 [last accessed August $31,2017]$.
50 Ericsson T, Blank A, Von Hagens C, Ashton M and Äbelö A: Population pharmacokinetics of artesunate and dihydroartemisinin during long-term oral administration of artesunate to patients with metastatic breast cancer. Eur J Clin Pharmacol 70(12): 1453-1463, 2014.

51 Dose-Escalation Study Evaluating the Safety and Pharmacokinetics of Artesunate in Patients With Hepatocellular Carcinoma - Full Text View - ClinicalTrials.gov. Available from: https:// clinicaltrials.gov/ct2/show/NCT02304289 [last accessed August 31, 2017].

52 von Hagens C, Walter-Sack I, Goeckenjan M, Osburg J, StorchHagenlocher B, Sertel S, Elsässer M, Remppis BA, Edler L, Munzinger J and others: Prospective open uncontrolled phase I study to define a well-tolerated dose of oral artesunate as addon therapy in patients with metastatic breast cancer (ARTIC M33/2). Breast Cancer Res Treat 164(2): 359-369, 2017.

53 König M, von Hagens C, Hoth S, Baumann I, Walter-Sack I, Edler L and Sertel S: Investigation of ototoxicity of artesunate as add-on therapy in patients with metastatic or locally advanced breast cancer: new audiological results from a prospective, open, uncontrolled, monocentric phase I study. Cancer Chemother Pharmacol 77(2): 413-427, 2016.

54 A Phase 1/2a Study of LON002 in Subjects With Advanced Solid Tumours - Full Text View - ClinicalTrials.gov. Available from: https://clinicaltrials.gov/ct2/show/NCT02263950 [last accessed August 31, 2017].
Received August 31, 2017

Revised October 3, 2017

Accepted October 5, 2017 